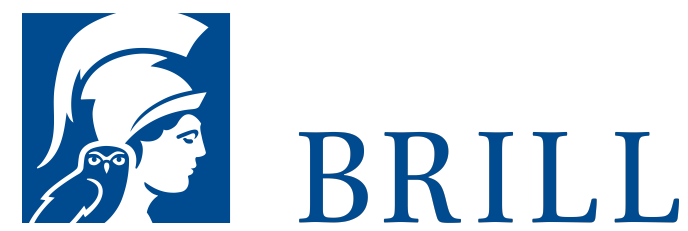

\title{
Der Sozialstaat hinter dem Haus
}

Wirtschaftliche Zukunftserwartungen, Selbstversorgung und regionale Vorbilder: Westfalen und Südwestdeutschland 19201960

\section{Author: Michael Prinz}

Dass Gärten nicht nur der Erholung, sondern in Krisenzeiten regelmäßig auch der Selbstversorgung und der Stadtbevölkerung als Zuflicht dienten, ist eine unumstrittene und in der älteren Generation noch weithin bekannte Tatsache. Wer aber weiß schon, dass einige der bekanntesten Vordenker der Sozialen Marktwirtschaft eine neue Gesellschaft um die Selbstversorgung bauen wollten. "Additive Autarkie" lautete ihre Rezeptur, um den, wie sie meinten, überforderten Sozialstaat beim Wiederaufbau zuentlasten. Diese auf den ersten Blick fremd anmutenden Forderungen einzuordnen und ihre weite Verbreitung im gesellschaftspolitischen Denken wie auch in der lebensweltlichen Praxis der Zwischenkriegszeit aufzuzeigen, nimmt sich die vorliegende Studie vor. Besondere Aufmerksamkeit findet die Wechselwirkung zwischen den langfristigen wirtschaftlichen Zukunftserwartungen der Zeitgenossen, der Krise des Weimarer Sozialstaates und der besonderen Popularität der Figur eines »Arbeiterbauern« als Existenzform des modernen Industriearbeiters. Große Bedeutung für die Rechtfertigung dieser Ideen besaßen regionale Vorbilder wie die Erwerbs- und Versorgungsstruktur Württembergs, des Saarlandes und von Teilen Westfalens. Dank der Verbindung von Erwerbsarbeit und Selbstversorgung schienen diese Regionen eine besondere Krisenfestigkeit aufzuweisen. Auf der Suche nach Zukunftsmodellen richtete die...

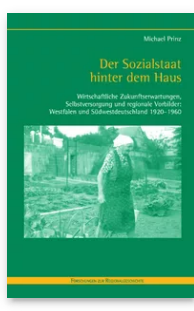

Pages: 454 Seiten, $27 \mathrm{~s} / \mathrm{w}$ Abb., $27 \mathrm{~s} / \mathrm{w}$ Tab.

Language:

German

Subjects: Global History, History Publisher: Brill | Schöningh

Series:

Forschungen zur Regionalgeschichte,

Volume: 69

E-Book (PDF)

Released online: O3 Feb 2020

ISBN: 978-3-

657-77332-9

List price

Hardback

Publication date:

14 Jan 2013

ISBN: 978-3506-77332-6 
Biographical Note

Michael Prinz, PD Dr., geb. 1952; wiss. Referent am LWL-Institut für westfälische Regionalgeschichte.

For more information see brill.com

\begin{abstract}
Order information: Order online at brill.com
+44330 333 0049 | customerservices@brill.com

Submission information: brill.com/authors
\end{abstract}

Titles published by Brill | Fink, Brill | mentis or Brill | Schöningh:

+49(o)71 5413279216 | brill@brocom.de 